\title{
Identifying Nursing Computer Training Requirements using Web-based Assessment
}

\author{
Naser Ghazi, Gitesh Raikundalia \\ School of Engineering and Science \\ Victoria University, PO Box 14428 \\ Melbourne, Australia
}

\author{
Janette Gogler, Leslie Bell \\ Austin Health \\ PO Box 5444, Heidelberg West \\ Melbourne, Australia
}

\begin{abstract}
Our work addresses issues of inefficiency and ineffectiveness in the training of nurses in computer literacy by developing an adaptive questionnaire system. This system works to identify the most effective training modules by evaluating applicants for pre-training and post-training. Our system, Systems Knowledge Assessment Tool (SKAT), aims to increase training proficiency, decrease training time and reduce costs associated with training by identifying areas of training required, and those which are not required for training, targeted to each individual. Based on the project's requirements, a number of HTML documents were designed to be used as templates in the implementation stage. During this stage, the milestone principle was used, in which a series of coding and testing was performed to generate an error-free product.

The decision-making process and it is components, as well as knowing the priority of each attribute in the application is responsible for determining the required training for each applicant. Thus, the decision-making process is an essential aspect of system design and greatly affects the training results of the applicant. The SKAT system has been evaluated to ensure that the system meets the project's requirements. The evaluation stage was an important part of the project and required a number of nurses with different roles to evaluate the system. Based on their feedback, changes were made.
\end{abstract}

Keywords-component; Training Needs Analysis (TNA); Nursing Compter Literacy; Web-based Questionnaire.

\section{INTRODUCTION}

The health industry has come to rely heavily on the use of technology across all practice areas. The use of IT is an integral part of the industry's daily practices. Nurses must be well skilled in the various forms of IT, due to the wide-ranging duties that are inherent in their role. Austin Health, one of the leading health-care facilities in Melbourne, Victoria, utilises a variety of electronic systems at its three campuses [1]; i.e., a computer system at front desk to enter in-patient data, administrative duties on each ward, and systems for rostering, work shifts, and electronic incidents reporting. Computer literacy is a barrier for the effectiveness of completing required tasks as not all nurses possess a high level of computer literacy skill. Nurses Training is a key tool in achieving the objective of a skilled workforce. It therefore becomes essential for Austin Health to have adequate training measures in place, to ensure that nurses are in a position to understand and possess the requisite skills to work with the relevant electronic systems.

Austin Health recognises that each individual begins employment with an existing skill set that varies, depending on their education, level of experience and the scope of their employment. Austin Health currently has a training method in place which sees all nurses, irrespective of their skill level and experience, undergo the same education. A system must therefore be developed to identify the current skill level of all current and incoming nurses in order to assess the appropriate type of training required to reach optimum knowledge and skill levels in electronic systems.

The System Knowledge Assessment Tool (SKAT) has been developed to meet Austin Health's objectives. The system is based on the use of an adaptive questionnaire, designed and developed in accordance with the principles of a Training Needs Analysis (TNA). The TNA involves a process of:

1. Determining the requirements of a particular nursing role

2. Establishing an individual's current skill and knowledge base

3. Identifying skill gaps and subsequent training solutions

4. Evaluating performance after training

\section{A. Aims}

The aim of this project is to replace the existing training method used by Austin Health with a new system that is efficient and cost effective for both the applicant and Austin Health. SKAT has been developed with regard to the current skill level and specific skill-set required for each nursing role.

The project aims to provide a range of benefits to Austin Health. SKAT provides:

- Efficient personalized training schedule and targeted training: SKAT provides a recommended training schedule which details the training required to meet the specific skill-set relevant to the applicant's role. Targeted training is considered most effective as it seeks to tailor the training to the needs of the applicant.

- Reduced training costs and training times: Training applicants only in areas where skill and knowledge gaps exist reduces training costs, as trainers will have less material to teach applicants. Training time will also be reduced as time will not be misused by teaching areas which applicants are already competent.

- Centralised skill progression monitoring: SKAT works as an effective skill progression tracking 
tool with the capability of monitoring each applicant from the first stage of the TNA, through to identifying the applicant's current skill-set and knowledge base, and evaluating performance.

- An Information gathering tool: The survey contains a range of questions, including some which are intended for administration and information gathering purposes.

\section{LITERATURE REVIEW}

The nursing profession has always required the processing of information [2]. By the late 1960's the first computer systems were installed in hospitals. Initially, these computer systems were installed to complete orders, charges and patient billing, which were previously performed manually [3]. However, very quickly the power of computers became known, and they gained more presence on nursing wards. Computers in hospitals offer nursing a unique challenge to define and validate its own practice [4]. Since the 1970's, nurses have contributed to the purchase, design, and implementation of IT solutions, as it has become a major element of the nursing role [5]. Nursing data processed by the computer is referred to as nursing informatics. This term was created by Scholes and Barber, and refers to computer technology as well as the computer system used to process input data into information [6]. Today, NI has evolved to be an integral part of health care delivery and a differentiating factor in the selection, implementation, and evaluation of health IT that supports safe, high-quality, patient-centric care [3]. Nowadays hospitals in the western world depend on computer technology to manage day to day tasks. For this reason, nurses are required to be skilled in some specific areas of computer use to enable them to perform all the tasks that are required in the health-care industry.

\section{A. Computer Literacy and Anxiety}

Computer literacy describes the level of expertise and familiarity an individual has with computers. The term generally refers to the ability to use applications rather than a program.

In today's highly technological world, the use of computers either directly or indirectly may not always be an easy or enjoyable task. Various factors have been shown to cause levels of computer anxiety among users [7]. Beckers and Schmidt stated that "an experienced computer user understands enough about computers in order to use them, more or less independent of specific software packages, reasons for use and computer hardware features (p.786)." Thus computer experience can be seen as the sum of all computer-related events. These events include:

1. The amount of time spent using computers at home, office, school, work or any other place.

2. Using computer hardware such as a personal computer, printers, and scanners; and the use of software applications such as word processing programs, databases, programming, e-mailing, and downloading software from the internet.

3. The frequency of use of computers, e.g. once a day, regularly, etc. The more often computers are used; the more responsive an individual will be to gaining skills and experience.

In an additional article in 2001 [8], Beckers and Schmidt proposed a model of computer anxiety. This model discusses six factors affecting an individual's levels of anxiety towards computers:

1. Computer literacy: An individual may feel nervous and uneasy when required to use a computer with no assistance. In contrast, a user with a high level of skill may feel much less anxious, as they have a higher level of experience, and thus more capable of completing tasks without assistance.

2. Self-efficacy: Self-efficacy is described as the confidence in users' capabilities to learn to use computers. Individuals who believe that they are incapable of using or learning how to use a computer will generally have higher levels of anxiety around computers.

3. Physical arousal in the presence of computers: Individuals who are not comfortable using computers, or who do not have many computer skills may show symptoms of anxiety in the form of sweaty palms, shortness of breath and seeming restless or unsettled.

4. Affective feelings towards computers: This factor identifies affective feelings such as likes and dislikes towards computers, by users. Generally, an individual who is not very skilled in the use of computers will have a negative feeling or dislike towards computers.

5. Positive beliefs: Identifies the benefits to society by using computers. In modern society, computers are perceived to be beneficial by saving time and effort when completing tasks.

6. Negative beliefs: Identifies negative factors which may increase user anxiety. Such effects of negative beliefs include feeling uncomfortable in the presence of computers, and may be related to previous unpleasant experience with computers, and thus invoke a negative connotation.

\section{B. Computer Literacy of Nurses}

The healthcare industry is constantly advancing, and care providers must recognise the need to sustain the required knowledge, skills, and resources required to communicate and manage information effectively in an electronic environment [9].

The computerised Health Information System (HIS) is expected to have great impact on health care practice in the years to come [10]. According to Dick and Steen, the HIS is "an essential part of technology for health-care today and in the future," and will lead to higher quality health-care, an increase in the scientific base of medicine and nursing, and a reduction in health-care costs [11].

Informatics competencies are an essential building block for evidence-based nursing practice [12]. Furthermore, the use of IT within the health-care industry is also expected to 
improve patient care in a cost effective manner by saving time, improving accessibility of information and less paperwork [13].

Although nurses do not need a high degree of computer expertise, effective skills will save time and reduce human error, for example, nurses who operate computers proficiently can quickly access health-care related information using computers. Nurses may also be able to provide more appropriate and efficient care to their patients [14].

The American Nurses Association (ANA) proposed that NI's have the following skills: computer literacy skills, information literacy skills, and overall informatics competency. These skills are important to help prepare nurses to begin their practice, and are also important for experienced nurses and informatics nurse specialists [15]. Having a personal interest in IT is considered the best solution to computer anxiety, as it maintains an individual's confidence when using computers.

Personal interest in IT has become a topic of major interest [16]. Since personal interest in IT may have a positive impact on an individual's computer literacy, Hsu, Hou, Chang and Yen [14] have constructed a generalised research framework, resulting with conceptual framework of factors influencing computer literacy. Four hypotheses were proposed and are as follows:

1. Demographic variables have an influence on nurses' computer literacy.

- The age of a nurse. Age has a significant influence on an employee's existing skill set and in some instances an inverse correlation to their training proficiency. For example, older nurses may not have had as much access to computer technology as their younger, more technology savvy colleagues. For this reason, it is understandable that younger nurses will generally have more computer skills, or even the ability to learn faster than older nurses.

- The length of a nurse's work experience. Skills which an employee has gained from previous experience will play a role in their computing skills. However, this depends on the duration of their past experience and their position during previous employment.

2. The education level of a nurse. Computer education has a positive impact on nurses' computer literacy. An employee's education affects their skill set as better educated employees generally possess a more comprehensive skill set. An employee's level of education may correlate to their training proficiency.

3. Computer experience. Previous experience in the use of IT provides practice for the individual, which in turn creates a more competent and confident individual. Previous experience includes IT applications in the health-care industry such as e-filing, patient database management and information seeking through the internet.
4. Personal interest in IT. The nurses' personal interest in IT affects the skill set as it positively correlates with nurses' training proficiency. For example, the more interest in IT shown by a nurse, the more attention the individual will pay towards learning new skills; thus a higher level of information stored.

Nurses are engaged in two broad types of information seeking. First, information is sought to help make decisions about the care of individual patients. Secondly, information is sought about broader topics within nursing.

The Delphi study by Staggers, Gassert, and Curran [17] is the most relevant work to the authors' project, and has studied the informatics competencies of nurses in a detailed manner. The Delphi study concluded that the informatics competencies of nurses are expressed in four levels of practice, with different requirements for each level:

1. Beginning Nurse: A beginning nurse is required to possess important information management skills which are utilised in this role through working with large amounts of information and files which must be well maintained to ensure efficient management. Excellent computer technology skills are essential in this role as beginning nurses must use computer applications to complete day-to-day tasks and perform managerial duties in their relevant role.

2. Experienced Nurse: An experienced nurse must be well-skilled and trained in a specific area of interest such as public health, education or administration. Much like a beginning nurse; an experienced nurse must be highly skilled in using information management and computer technology skills to support the specific field of practice.

3. Informatics Nurse Specialist: An informatics nurse specialist is a registered nurse with a superior level of knowledge and skills specific to information management and IT. This role focuses on the education, administration, research and clinical practice information needs for the nursing role.

4. Informatics Innovator: An informatics innovator must be capable of performing research and generate theory, based on informatics. The informatics innovator must possess the foresight into possibilities, used to facilitate the development of informatics practice and research, leading to more effective time management to perform tasks. Thus, this level of nursing relies heavily on a high level of understanding and skills in IT and information management, and the understanding of the correlation of systems and disciplines.

The Delphi study identified the nursing informatics in four levels of practice. The results cannot be compared to those of the authors' project as the Delphi study identified nursing informatics in a more generalised manner, whereas the authors' project identifies the level of computer literacy of individual nurses, to generate a targeted training schedule. 


\section{Nurses Computer Education}

Previous sections discussed assessing registered or graduate nurses' computer abilities, and existing skills. The following section discusses computer education and assessing undergraduate nurses' computer skills.

Information literacy development results from students' learning experiences within a number of subjects through their undergraduate years [18]. This ensures incremental development and enables students to transfer skills and knowledge across the undergraduate program at the same time. Wallace, Shorten, Crookes, McGurk, and Brewer proposed a number of strategies for introducing information literacy into the curriculum, for instance;

- Providing feedback regarding assessment information literacy skills and knowledge

- Articulating these skills in classrooms to students

- Developing subject aims and objectives

- Specifying the development of skills and knowledge involved

- Focusing on the process in addition to learning and providing the chance for discussing the process

When a teaching unit such as a department, school or faculty adopt them as a whole, these strategies are extremely effective. However, the adoption of such strategies across a teaching unit requires many academics to change the way they currently teach, therefore this approach occurs infrequently.

One of the critical issues facing the nursing profession is the lack of knowledge in IT and use of evidence-based practice, resulting from a serious lack of NI content in education and training programs. There is a pressing need for a computer driving license, which is a computer literacy certification program provided by the European Computer Driving License. The certification is recognised and supported by national governments and computer societies to assist nurses in becoming competent to use electronic information systems [19].

The policy of Nursing Informatics Australia [20], maintains that nursing education providers should ensure that nursing informatics education is included within the teaching materials in nursing programs. This will help establish the effective use of IT solutions and to support consumer-based care among new nursing graduates.

Nursing education providers should also provide students with opportunities to learn about the use of informatics tools to promote effective clinical decision-making as well as safety and quality. Providing students with these opportunities will enable the maximisation of workforce capabilities in the healthcare field.

It is important that nursing educators provide an online learning community which can be accessed anywhere at any time, and provides a central resource for users. This increase in exposure to IT and systems within nursing curricula is important as it provides practice with various IT applications.
An advanced level of education in nursing informatics should be provided at a postgraduate level, to enable the high proficiency in areas such as informatics solution planning, development and management to provide an opportunity to develop more skills and knowledge in nursing informatics.

Nurses should be competent in nursing informatics as a main knowledge component before obtaining national registration and accreditation it is essential that nurses are competent in nursing informatics as the health-care industry is technologically advancing, and many aspects of the nursing role require a high level of computer skills. Nursing informatics education should be standardized with guidelines to measure the understanding of informatics competencies. This can be done by establishing national competency standards. Nurses must be educated in nursing informatics, as it is imperative that they keep abreast of informatics.

The nursing facility should be given enough support, to prepare for and enable the most effective teaching of health informatics. Health informatics is an integral part of the nursing role, and thus it is important that the nursing faculty is well prepared to teach health informatics. Special grants should be provided by governments to foster a supportive and effective educational environment in which nursing informatics can be taught.

Research topics should include the essential health informatics skills that a nurse should possess, the teaching methods and delivery of teaching to nursing students, as well as the most effective an efficient program design for nursing informatics subjects. Furthermore, the research topics should include the method of evaluation of the impact of the informatics education on clinical use.

In order to provide safe and effective nursing care, nurses must be capable of accessing an expanding information base, developing skills needed to manage the technology required for information retrieval and using this information appropriately to solve clinical problems. Ideally, the skills necessary to be a discerning user of information should be developed in preregistration nursing programs.

\section{SKAT REQUIREMENTS}

This project is designed and developed for use by Austin Health. There are approximately 750 public hospitals and 500 private hospitals in Australia, accommodating more than 50,000 hospital beds for patients, over 7000 staff, of which there are 3200 nurses. Austin Health is a major health-care institution in Victoria and comprises three facilities: Austin Hospital, Heidelberg Repatriation Hospital and the Royal Talbot Rehabilitation Centre [1].

\section{A. Austin specific problem}

With an increasingly large amount of new staff employed at Austin, it is understandably difficult to track the level of computer skills of each staff member. This creates a problem when new staff members undertake generic training that may not be required, as the individual may already have the knowledge and skills and only need to understand the manner in which the processes are used at Austin. 
Consequently, with minimal training effort they can become proficient users of the system. However, the challenge lies where there are other staff members with little or no skills and knowledge, and therefore need a greater level of in-depth training. Austin has identified a benefit in that targeted training has the potential to reduce costs and lead to improved outcomes in a range of areas.

\section{B. Project Goal}

The goal of this project is to provide a computer-based test that assesses the computer literacy level of each nurse, thereby determining the learning modules required to meet the set competency levels. The testing application is adaptive; future questions will be determined by previous answers provided by the nurse.

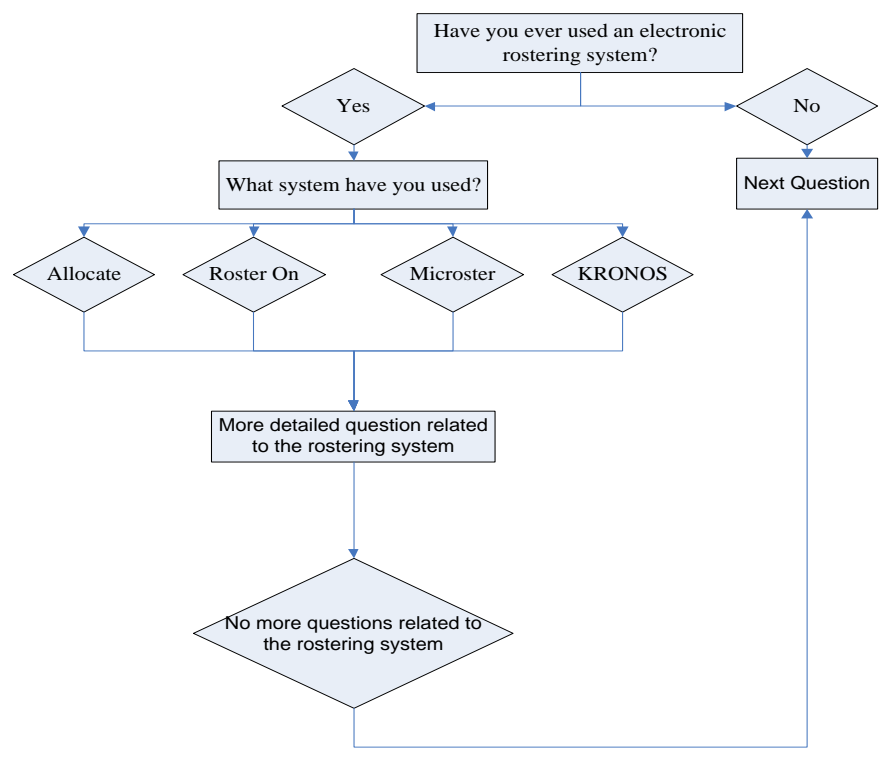

Figure 1: KRONOS Example

Fig. 1 demonstrates an example of the adaptive testing application. In this example, the main question 'Have you ever used an electronic rostering system?' must be answered by the applicant in order to progress to the next question.

If the applicant's answer is 'No,' the test questions will change to suit an applicant with no previous rostering experience. However, if the applicant's answer is 'Yes,' the application will display more detailed sub-questions to effectively probe the applicants past history with computer systems, and therefore obtain as much information as possible from minimal questions. The course of questioning will test for general computer skills, skills within specific programs and software packages and other systems used to determine the level of the applicant's technical knowledge.

The application will process each answer and provide a collective result indicating the technical skill level of the applicant and the training modules required to meet the required skill set. The results for each assessment will be saved in the employee's respective file within the hospital database.

\section{Austin's Nursing Roles}

Austin Health Institute employs eight different nursing positions.

1) Nurse Unit Manager (NUM): A NUM is a Registered Nurse (RN) who supervises nurses in a specific unit of the hospital. This role involves managing the care of patients and the responsibilities of nurses, budget management and rostering of staff. The role of a NUM also involves the management of the Patient Services Assistant and the ward clerk [21].

2) Assistant Director of Nursing (ADON): The ADON is a senior management position within Austin Health. Most of the ADONs are the after-hours site managers responsible for the running of the hospital in the evening, overnight and on weekends. This role requires exceptional communication skills to manage bed occupancy, staffing issues, patient and relative issues that arise as well as emergency and disaster management. The ADON also has a role to report back to the Deputy Director of nursing [22].

3) Associate Nurse Unit Manager (ANUM): The ANUM has significant responsibilities. In the absence of the Nurse Manager, ANUM has the responsibility of undertaking tasks delegated by the Nurse Manager. As members of the hospital's middle management team, the ANUM is usually the nurse coordinator of the shift and takes on a portfolio of responsibility in the ward or the department [23].

4) Clinical Nurse Specialist (CNS): A CNS has advanced practice skills and holds graduate degrees (master's or doctorate) in a specific field of medicine such as neonatal, developmental disabilities, diabetes, oncology or pediatrics [24].

5) Clinical Nurse Consultant (CNC): A CNC provides direct patient care and creates and implements health care protocols. The $\mathrm{CNC}$ ensures that clinical employees abide by government laws and regulations when performing tasks [25].

6) Clinical Support Nurse/ Continuing Nurse Educator (CSN/CNE): A CSN provides teaching and support to Graduate Nurses (GN), year program participants and other staff in a manner consistent with achieving learning outcomes set by the Clinical Nursing Education Department (CNED). This role is ward based and supports graduate year nurses in their clinical roles.

A CNE is a Registered Nurse who coordinates and ensures appropriate delivery of specific education program components, short courses or study days; to achieve outcomes set by the CNED [26].

7) Registered Nurse (RN): An RN is a qualified nurse with a degree in nursing. The role of an $\mathrm{RN}$ is much broader than the other seven nursing positions, and mainly involves first- hand interaction with patients, and no managerial role [27].

8) Enrolled Nurse (EN): An EN is a second-level nurse who offers medical care under the supervision of an RN [28]. 


\section{Austin's Existing Systems}

Austin Health uses a number of systems which nurses have to be trained to use, in order to fulfill the responsibilities for the role they occupy.

1) KRONOS: Electronic rostering or e-rostering is the process of using the computer's power to the task of rostering. Essentially, e-rostering considers the requirements, skills, shift history, preferences of staff members and creates a schedule that not only meets the requirements but also complies with laid-down rules of scheduling.

KRONOS is the computerised roster and timecard management system used by Austin Health. It has the capability for staff to make electronic requests for leave, accruals can be viewed and reports can be printed [29].

2) TrakHealth: TrakHealth develops and markets TrakCare, Austin Health's patient administration system. The electronic Patient Records (ePR) in TrakCare are operational. It uses the database identifier or the Patient Master Index (PMI) for all patients receiving services at the hospital to create and store patients' unit medical record numbers. It also provides a full range of clinical, administrative, lab and community care capabilities, unified in a single data repository [30].

3) Scanned Medical Record (SMR): SMR is a web-based system that is used within Austin Health for scanning the patients' printed medical records. The records are scanned and saved in the database in a Portable Document Format (PDF) format once the patient is discharged. The records can be monitored, printed or emailed from anywhere in the Hospital and at any time [31].

4) Online Radiology System: The Picture Archiving and Communications Systems (PACS), is the Online Radiology System used by Austin Health. PACS allows authorised users to access radiological images online to multiple users, 24 hours a day, on all Austin Health sites. PACS uses a radiology web browser called AGFA Web1000 to view the radiology images on the computer $[32,33]$.

5) Risk Management: RiskMan is a system which electronically records all clinical and non-clinical accidents or misses. Austin Health is committed to promptly reporting and responding to incidents and hazards, to ensure the best possible outcomes for all people affected and to identify and control future risk to staff and members of the community [34].

6) Budgeting system: PowerBudget is a financial software application for the NUM used to anticipate, forecast and manage staff costs and consumables in each ward or department. The system provides intelligent budget calculations using cost driver relationships generating instant results based on the user's requirements [26].

7) Electronic medication administration system: Cerner Millennium is the new electronic medication administration system that has been implemented within Austin Health. This system was initiated by the Victorian Department of Health as part of the HealthSMART program; a state-wide plan aiming to modernise and replace IT systems throughout the Victorian Public Health-care Sector [26].

8) Health-e Workforce Solutions (HWS): HWS is a software system designed to facilitate the management and analysis of the nursing workforce, especially the management of replacing staff on sick leave, roster vacancies and annual leave. The application determines the requirements for each area related to nursing classifications and roster requirements. This provides information on the Exchange Traded Funds (EFT) requirement for the respective ward or area and alerts managers to a shortfall in staff and level required.

Nurses in charge of the shift are able to enter staff sick leave and replacement requirements, while managers have the capability to access greater functionality to ensure that rosters are created with the correct level of staff for each shift [35].

9) Comprehensive Human Resource Integrated Solution (chris21): Chris21 is the Human Resource and Payroll Management system used within Austin Health. Chris21 builds a complete history of every employee which creates the ability to build HR and payroll strategies based on certain requirements. The system delivers a dedicated, multi-functional and highly-flexible HR solution [36].

\section{E. Overall System Description}

SKAT gauges the level of computer skills of each individual and comprises two parts; Assessment component, and Administrative component. These two parts work together to assess the level of computer literacy, based on the input provided by the applicant.

1) Assessment Component: The Assessment component of the system allows applicants to enter their personal details and choose their appropriate role. SKAT uses this information to determine which corresponding questionnaire will be administered to the applicant. The questionnaire encompasses three main categories; General IT Skills, Professional IT skills, and Hospital Systems skills.

The General IT Skills category includes a number of subcategories to obtain a thorough understanding of the individual's abilities in using various IT applications

- General information

- Social networking

- Search engines

- Personal use

- Internet browsing

The category of Professional IT Skills helps to identify which computer applications have been used previously by the individual; to gauge the level of competency in the use of IT at work. This category covers the following sub-categories:

- Emailing skills

- Microsoft Word

- File management

- Microsoft Excel

- Microsoft PowerPoint 
The Hospital Systems category focuses more specifically on IT systems which are currently used in the health-care system, and assesses the level of exposure to these systems to gauge the individual's experience. This category explores the following sub-categories:

- Electronic rostering

- Electronic casual staff management system

- Electronic risk management

- Electronic budgeting

- Clinical systems

- Electronic medication administration

- Mental health

- Residential aged care

- Community care

The applicant must answer all questions before submitting the questionnaire; the software then generates a report with the recommended training for the particular role of the individual.

2) Administrative Component: The administrative component presents the System Administrator with the ability to control the functionality of the software. The system provides an interface tailored to each user type, according to input provided. Elements of the questionnaire are adaptive, that is, the next question presented will be determined by preceding answers.

The course of questioning tests for general computer skills, health business and clinical systems skills used by different levels of registered nurses within Austin Health, as part of the daily requirements, to determine the level of the applicant's technical knowledge. This will enable training to be specific to each applicant, and result in time efficient, and cost efficient training.

Fig. 2 summarizes the Austin Health Survey System Use Case. It illustrates the functions that each of the three user types can perform, and shows the differences between the three user roles. The Figure shows that the Applicant can only perform one task, whereas the System Administrator can administer all functions but one. As shown, Managers and System Administrators have shared access to certain functions.

\section{SKAT DESIGN}

The design of SKAT system encompasses three designing stages; the Questionnaire design, Database design, User Interface (UI) design, and Decision Making design.

\section{A. Questionnaire Design}

The questionnaire encompasses three main categories, with 19 sub-categories. The multi-level design of the questionnaire simplifies the display of the questionnaire, by grouping questions into sub-categories, and these sub-categories into more general categories. This hierarchical design is a much simpler way of forming the questionnaire, as questions are grouped in relevant categories and sub-categories to allow more efficient navigation through the questionnaire.

\section{B. Database Design}

The questionnaire database controls the required information for the applicant from the start to completion of the questionnaire, and manages the following steps:

- Personal details of the applicant

- The role of the applicant

- The most appropriate survey required

- Survey questions

- Corresponding possible answers

- $\quad$ Save the report for each survey

The Database Entity Relationship (ER) diagram, Fig. 3 illustrates an important part of designing the database. It depicts the main entities required for the database with the corresponding attributes for each entity. The figure also illustrates the relationship between the entities, as an example, one or more $\left(1 .{ }^{*}\right)$ applicant might have the same position (1..1).

\section{User Interface Design}

HTML documents were developed as mockups of the system's user interfaces which are designed as a model of the software to show the appearance of the application's design. The development of the UI design reached its final stage after a number of changes were made, including changes to the UI, grammar, categorical structure, and questions, based on feedback from the project supervisors at Austin Health. The UI Mockups are used as templates to implement the application.

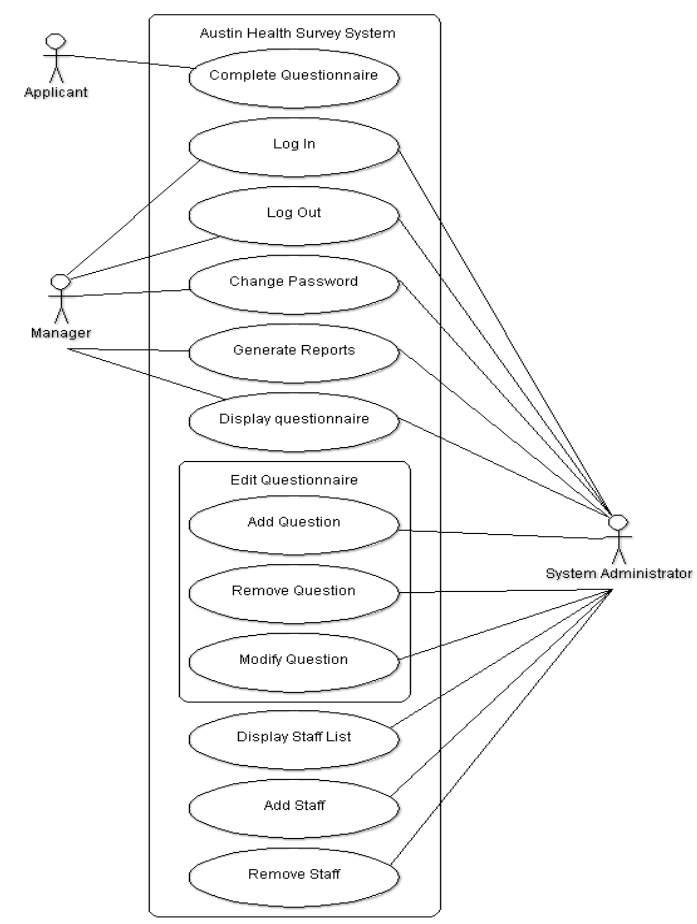

Figure 2: Austin Health Survey System Use Case 


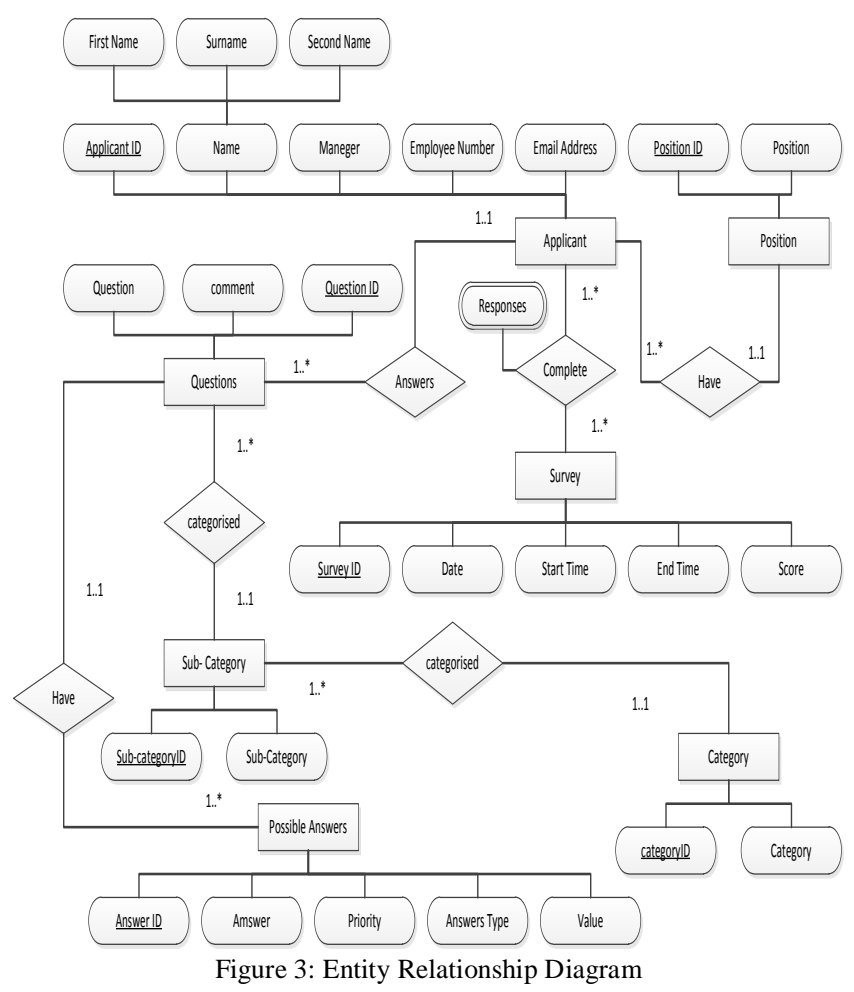

\section{Decision Making}

The Decision Making component is the process responsible for determining the required training for each applicant. The system offers three versions of the questionnaire, based on the applicant's position. Training recommendations vary, according to the needs identified through the applicant's responses and their role.

A training priority procedure will apply, and will have two approaches:

- Setting a priority level for a specific field or possible answer. This approach is useful, for example where an applicant selects 'no' in a question regarding the applicant's use of a particular system. As a result of no previous experience in this system, SKAT identifies that a higher priority of training is necessary.

- Answers will be rated from 1 to 5 , and will be determined according to the applicant's score in the questionnaire. A lower score indicates lower skills, making training requirements a higher priority for that applicant. However, a higher number indicates a higher level of skills, making training requirements a lower priority for the applicant.

Each role will have a Decision Support System (DSS) for priority training as shown in Table 1.

TABle 1. DECISION MAKING PRIORITY List

\begin{tabular}{|l|l|}
\hline Priority 0 (P0) & no training \\
\hline Priority 1 (P1) & training must be within 2 weeks from employment \\
\hline Priority 2 (P2) & training must be within 4 weeks from employment \\
\hline Priority 3 (P3) & training must be within 6 weeks from employment \\
\hline
\end{tabular}

The DSS shown in Table 1 illustrates the four priority levels determined through the results of the questionnaire. The priority time frames have been set by Austin Health, as they are the most appropriate intervals for the roles and positions available.

\section{SKAT SYSTEM}

The SKAT system consists of 24 web pages including the Master page, Header page, Questionnaire starting page, Applicant's information page form, Questionnaire pages, Closing page, and Report Page. SKAT is a web-based application which will run on Austin Health's local server (Microsoft Windows Server 2003). SKAT will be accessed and used by multiple users simultaneously, to facilitate various functions. The programming languages used to program the SKAT were ASP.net, HTML, and C Sharp (C\#).

The Author used Microsoft Visual Studio 2010 Professional, Framework 4.0. ASP.net was chosen as the server at Austin Health conflicts with Java and Java Script. In view of the fact that Austin Health uses Microsoft products, this was the main reason for choosing Microsoft Visual Studio 2010 to develop the software. Developing the software in ASP.net will increase the systems compatibilities, and reduce conflicts between programming language and servers.

The first author used the milestones principle, in which the coding is tested after each major step or after adding a new function. This method helps to correct all developing errors in each stage, which will increase the chance of producing bugfree software.

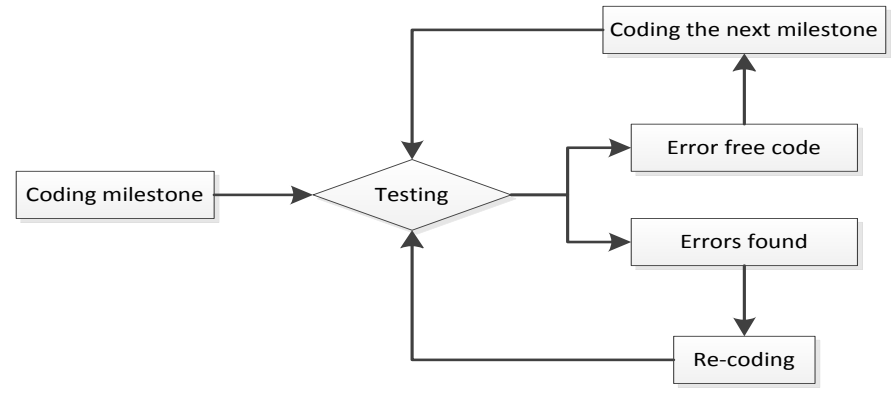

Figure 4: Testing milestone

The process of testing as sown in Fig. 4 begins by testing at each milestone stage, and if the code contains no errors, the next milestone will be tested. However, if errors are found in the code, the author must re-code and test, to ensure that no further errors exist in the code.

\section{A. SKAT Pages}

The primary page a user will view upon beginning the survey is the SKAT Welcome page. This page serves the purpose of providing a short introduction to SKAT, including a brief summary of the components of the questionnaire, and question type. It also provides simple instructions about starting the questionnaire and completing it.

The Applicant information page shown in Fig. 5, requires the user to enter general personal details such as position, name, manager, employee number and email address, and serves the purpose of identifying the user. 
APPLICANT INFORMATION

Please ill in your personal information

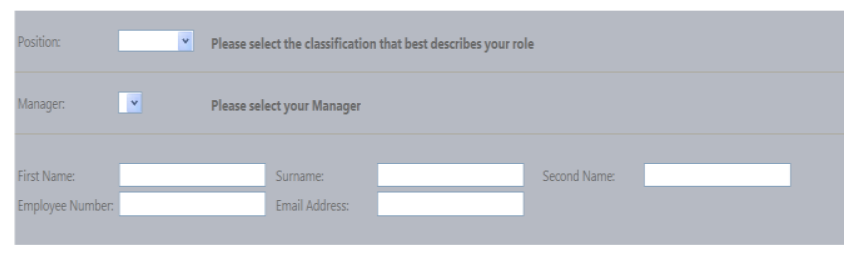

First Name, Surname, Postition, and Email Address, Are required

Start

Figure 7: Applicant's Information

The information entered will be gathered to ensure that the appropriate surveys will be available to the user, and to record information about start and finish times of questionnaires, and applicants' details.

GENERAL IT SKILLS
GENERAL INFORMATION
How often do you use the computer?
OFrequently ORegularly OOccasionally
Where do you use computers ?
Please tick those applicable
$\square$ Home $\square$ Work $\square$ University $\square$ Library
You use computers for?
Please tick those applicable
$\square$ Work $\square$ Study $\square$ Entertainment

Figure 5: General IT Skill's page

Fig. 6 illustrates the first set of questions that applicants must answer. These questions are organised into subcategories. The questions have been designed to obtain general information about the level of computer use quickly. The applicant must answer all questions before pressing on the 'Next Page' button to move to next page.

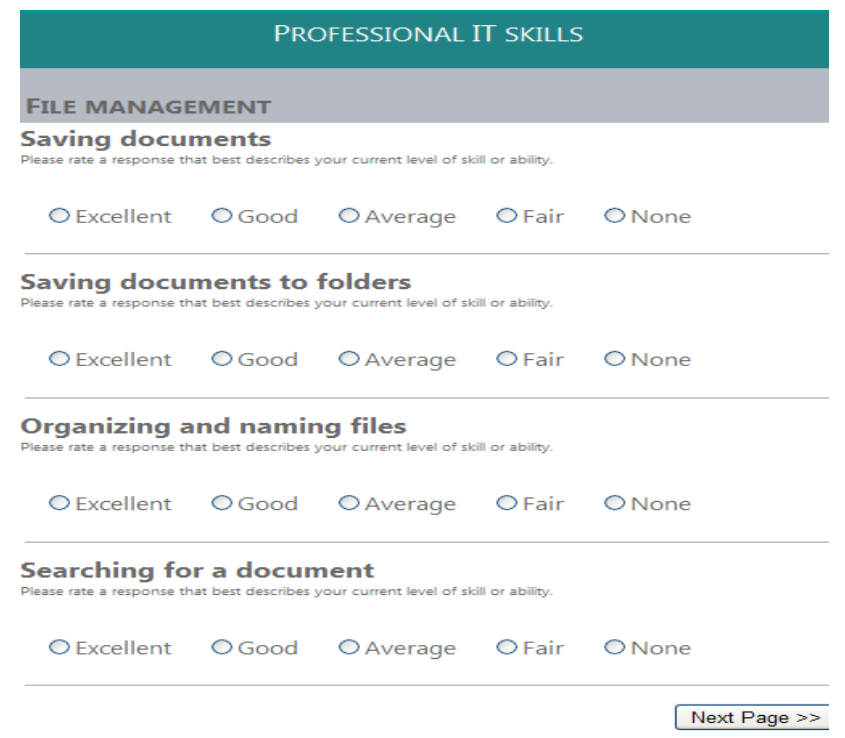

Figure 6: Professional IT Skills page
The Professional IT Skills page, shown above in Fig. 7 presents a set of questions from a different category. The responses given to these questions determine the applicant's ability to complete basic computer tasks, such as saving, maintaining and locating files. The questions on this page have been set up to provide the most amount of information as efficiently as possible. Upon completion of the questions on this page, the applicant must press the 'Next Page' button to continue to the following sub-category.

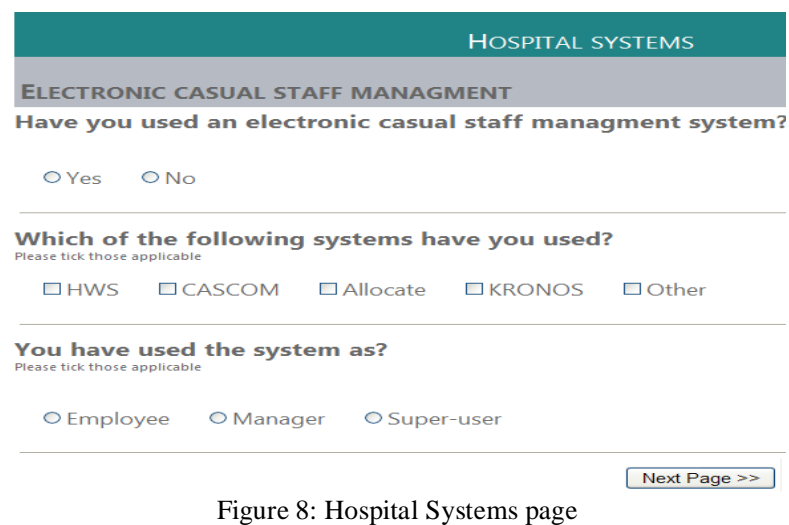

The last set of questions is displayed in the Hospital Systems page as shown in Fig. 8. These questions are more specific to the role of the applicant, as they seek information about computer systems and the area of work the systems have been used in. As this is the final page of this category, the applicant must press the Submit button to complete this section.

Upon completion of the questionnaire, a closing page is displayed, with a message to thank the applicant for completing the questionnaire. This page also contains a link to the corresponding report for the applicant. The report provides details of answers provided for the individual questionnaire.

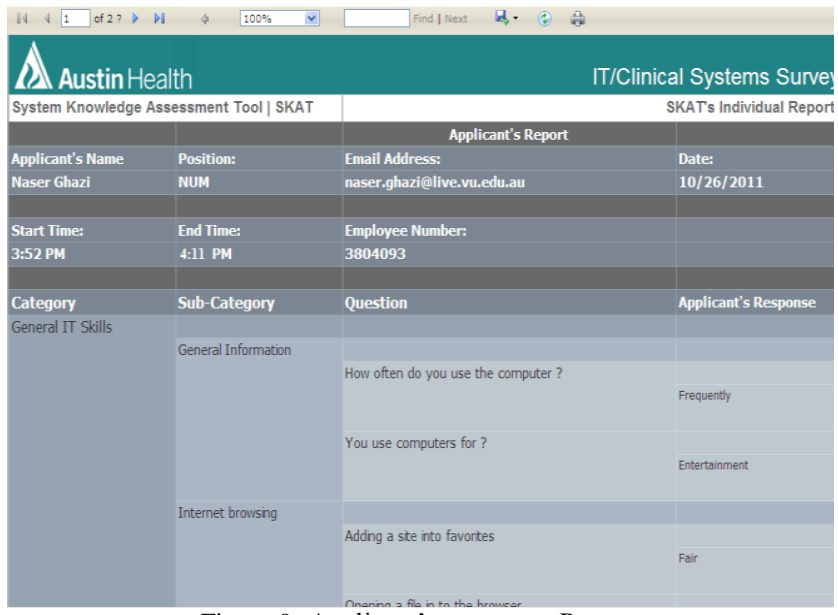

Figure 9: Applicant's responses Report

The Applicant's Report provides a list of answers provided by the applicant, as well as an overview of the applicant's personal information such as name, email address, position and employee number, displayed in the information bar. The report also details the date, start and finish times of the questionnaire. 
The page contains a toolbar with options to skip pages, refresh the page, zoom in or out, or to find keywords by using the search function. The toolbar also provides an option to save the report as a PDF, Microsoft Word document, or a Microsoft Excel document, as well as printing the report.

\section{B. SKAT Validation}

Two types of validation were applied to SKAT. The first type of validation is to check SKAT's navigation, to ensure that all mandatory questions are answered before navigating to the next page. The second type of validation involves checking user inputs to ensure that they meet the requirements of the field, for example a particular answer field may only allow numerical digits to be entered. Validating this field ensures that the applicant cannot enter text into the field.

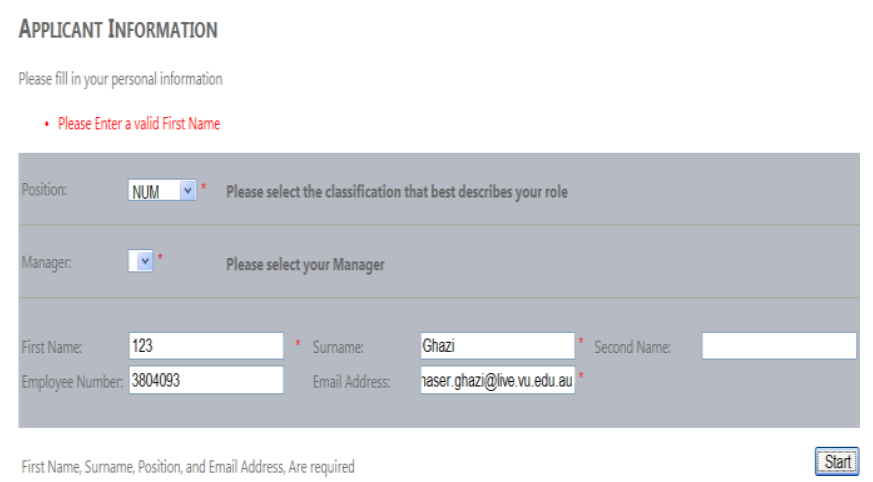

Figure 10: First Name field Validation

A first name field validation was performed on the Applicant Information page to validate the applicant's input. In Fig. 10, the applicant entered numeric figures in the 'first name' field. Upon validation of this page, an error message appears, notifying the applicant that they must enter information into the required field. This field does not allow numerals, punctuation marks and symbols to be entered. Only upper case or lower case letters of the alphabet may be entered.

Required answer validation was performed on the questionnaire pages to ensure that the questionnaire will not proceed unless all questions have been answered. If a question is not answered, an error message will be displayed above the relevant question, advising the applicant that an answer is required.

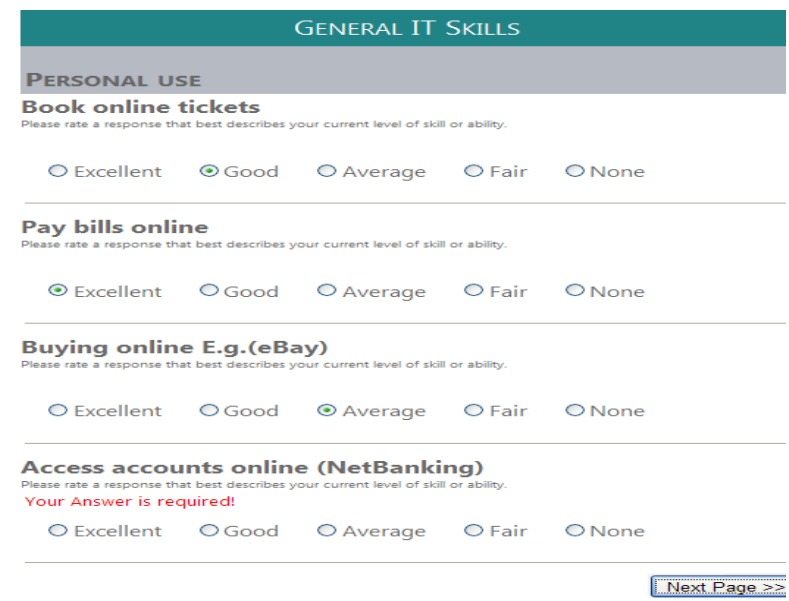

Figure 11: Required Answer Validation
Fig. 11 shows an example where the last question was not answered, and an error message prompting the applicant to answer the question.

\section{SKAT Evaluation}

Evaluation is an important element of system development. It ensures that the system developed meets the client's requirements. Furthermore, with regard to SKAT, it provides information about the effectiveness and efficiency of the system, based on the experiences by nurses testing the system. Evaluation is also a critical part of development, as it enables nurses testing the system to provide suggestions and comments to improve SKAT.

The most appropriate method of evaluation was identified as a simple questionnaire, due to time and staff constraints present within Austin Health. This questionnaire is the most efficient way of obtaining feedback about SKAT, and the most suitable method for Austin Health, as it also enables testers to leave comments to improve the system, in addition to verbal suggestions during the completion of SKAT.

The evaluation questionnaire, as administered to test subjects is as follows:

Evaluation Questionnaire
1- Was the system easy to use?
2- Was it clear what to do in each step?
3- The system needs written instructions?
4- Were the questions in the right sequence and order?
5- Some questions are unnecessary (please specify if any)?
6- The questions are clear and easy to understand?
7- Was the questionnaire long?
8- Having the questions in categories is a good idea?
9- Some categories were irrelevant (please specify if any?
10- I am satisfied with the system (If yes please specify why)?
11- Do you think the system is useful?
12- Do you think the system will improve the training requirements?
13- The system meets the training needs for the different roles of nursing?
14- The font size and the colors are suitable in the system?
15- Do you think that all employees (staff groups, staff members) should be surveyed (Please specify your answer)?
16- Any other suggestions?

Figure 12: Evaluation Questionnaire

Fig. 12 illustrates questionnaire is a suitable method of evaluating the system in terms of ease of use from the applicant's perspective. It also provides an opportunity to identify improvements which can be made to SKAT.

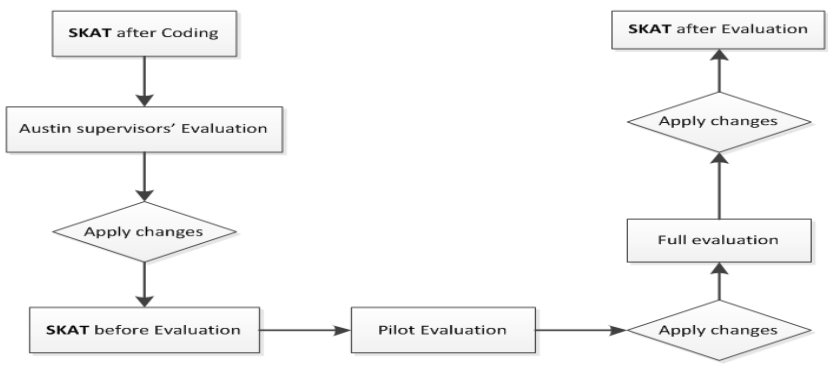

Figure 13: Evaluation Process

Fig. 13 illustrates the flow of steps taken in the process to evaluate SKAT. The first step in this process is the Austin supervisors' Evaluation, the second step is the pilot evaluation, and based on these results, changes were applied to SKAT. The 
third and final step is a full evaluation, which involved applying final changes to SKAT, based on feedback provided by evaluators, before delivering the final version of SKAT to the client.

\section{A. Pilot Evaluation}

Upon completion of programming and testing, a User Acceptance Test (UAT) was performed on SKAT. When evaluating the system, the Austin supervisors completed the SKAT as applicants and identified grammatical errors which needed to be corrected. Grammatical errors are the only changes which can be made at this stage, before the pilot evaluation is conducted. The errors were discussed with the author and changes which needed to be made were identified.

A pilot evaluation was then conducted, using nurses in the NUM and CNS roles. The NUM participated in the pilot evaluation, as the NUM is presented with the most questions in the questionnaire, as it is a more senior role. The pilot evaluation concluded that more grammatical errors were identified, and some questions needed to be re-worded to improve understanding by applicants. The NUM and CNS provided suggestions for changes to the SKAT, and as these suggestions were also raised by the Austin supervisors after the UAT, the changes were applied.

After the CNS and NUM undertook the pilot evaluation, repetitive and unnecessary questions were identified, and consequently discussed with Austin supervisors who then took necessary steps to amend the questionnaire.

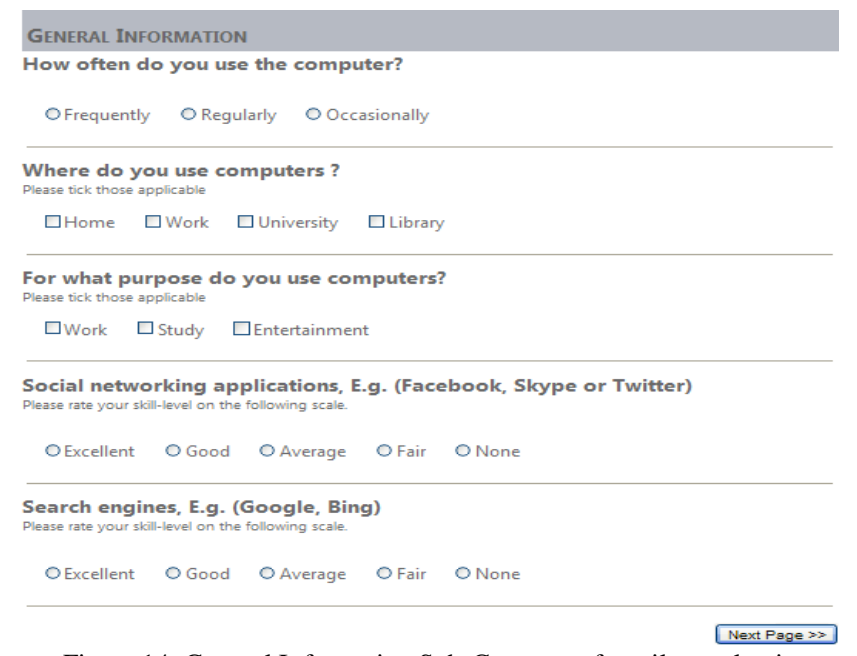

Figure 14: General Information Sub-Category after pilot evaluation

Fig. 14 depicts the General Information page after the UAT and pilot evaluation were conducted. Austin supervisors, NUMs and CNSs identified that some questions in the Social Networking and Search Engines pages were repetitive and unnecessary as they were irrelevant to the industry. Consequently, these two sub-categories were incorporated into the General Information sub-category. Two sub-categories have been removed completely from the questionnaire, thus reducing the number of sub-categories in the SKAT from 19 to 17 , as very detailed information about these sub-categories is not required. The total number of questions has also been reduced from 87 to 74 questions.
Table 2 explains reasons for the removal of thirteen questions in SKAT. It summarizes information about the subcategories, questions and reasons they were removed from the questionnaire.

TABLE 1. REMOVED QUESTIONS

\begin{tabular}{|l|l|l|}
\hline \multicolumn{1}{|c|}{ Question } & Sub-Category & \multicolumn{1}{|c|}{$\begin{array}{l}\text { Reason of } \\
\text { removing }\end{array}$} \\
\hline $\begin{array}{l}\text { Do you use social networking } \\
\text { applications? }\end{array}$ & $\begin{array}{l}\text { Social } \\
\text { Networking }\end{array}$ & Repetitive \\
\hline Face book & $\begin{array}{l}\text { Social } \\
\text { Networking }\end{array}$ & Repetitive \\
\hline Twitter & $\begin{array}{l}\text { Social } \\
\text { Networking }\end{array}$ & Repetitive \\
\hline MSN-Messenger & $\begin{array}{l}\text { Social } \\
\text { Networking }\end{array}$ & Repetitive \\
\hline Yahoo-Messenger & $\begin{array}{l}\text { Social } \\
\text { Networking }\end{array}$ & Repetitive \\
\hline Skype & $\begin{array}{l}\text { Social } \\
\text { Networking }\end{array}$ & Repetitive \\
\hline Do you use search engines? & Search Engines & Repetitive \\
\hline Google & Search Engines & Repetitive \\
\hline Bing & Search Engines & Repetitive \\
\hline Yahoo & Search Engines & Repetitive \\
\hline MSN & Search Engines & Repetitive \\
\hline Pay bills online? & Personal Use & Repetitive \\
\hline $\begin{array}{l}\text { Opening a file into the } \\
\text { browser? }\end{array}$ & Internet Browsing & Irrelevant \\
\hline Text Editing? & Microsoft Word & Repetitive \\
\hline Saving documents to folders? & File Management & Repetitive \\
\hline & & \\
\hline
\end{tabular}

The questions in the two sub-categories; Social Networking and Search Engines, as well as others were removed from SKAT as they do not affect the applicant's overall score in the survey. These two sub-categories provide a resource for information gathering purposes within Austin health.

TABLE 2. ADDED QUESTIONS

\begin{tabular}{|l|l|}
\hline \multicolumn{1}{|c|}{ Question } & \multicolumn{1}{|c|}{ Sub-Category } \\
\hline $\begin{array}{l}\text { Social Networking applications, E.g. (Face book, } \\
\text { Skype, or Twitter) }\end{array}$ & General Information \\
\hline Search Engines, E.g. (Google, Bing) & General Information \\
\hline
\end{tabular}

Table 3 shows that two questions were added to SKAT, under the General Information sub-category. These have been moved from two other sub-categories, as discussed under Table 2. These two sub-categories were amalgamated into only two questions in the General Information sub-category as the original questions were deemed too repetitive. The new categorizing of these two questions provides a much simpler way of gathering this information.

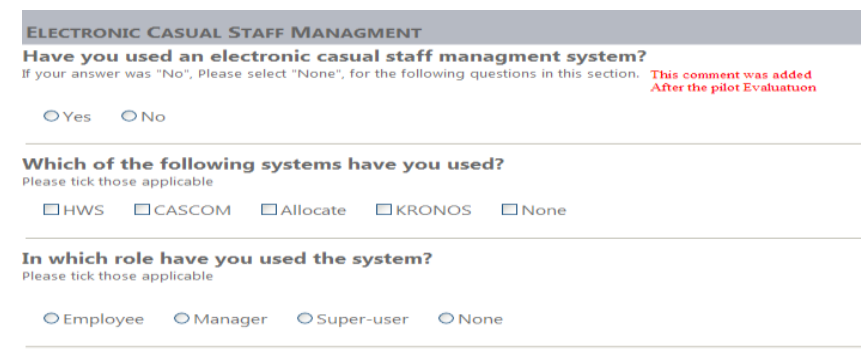

Figure 15: yes/no questions after pilot evaluation 
Fig. 15 illustrates the changes made according to the UAT and pilot evaluation. The option 'None' was added to questions in all sub-categories starting with a yes/no question. Previously, the questionnaire did not list 'None' as a response option; hence the applicant was obliged to choose an answer before proceeding to the next sub category, even if the answer was not applicable.

\section{B. Evaluation}

The full evaluation stage is the final step in the evaluation process before delivering the complete system to the client. This step is considered a re-evaluation of the changes made to the system after the pilot evaluation to ensure that the system works well, and can be easily understood by the applicant.

The full evaluation process used in SKAT involved the participation of five nurses with the following roles: NUM2, NUM3, ANUM, CNS2 and RN. These nursing staff tested the system and completed the questionnaire sample, and generally had positive attitudes towards the system. Based on the full evaluation feedback, the following changes were made to SKAT.

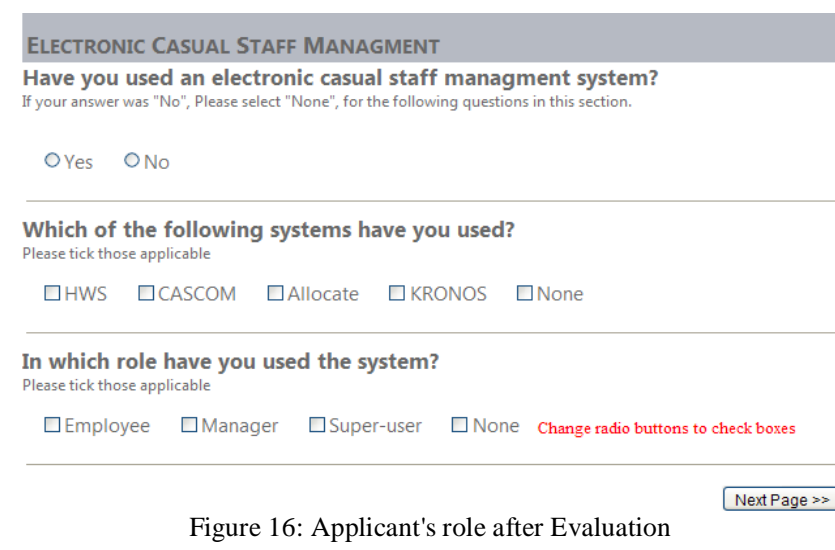

After the evaluation process, the Author and Austin Health supervisors agreed that it is simpler and easier for applicants to comprehend if they changed the possibility to have more than one answer option, or to tick all answers that apply. NUM2 found this to be an issue. Consequently, changes in coding were made to change radio buttons into check boxes to allow more than one answer to be selected. Fig. 16 demonstrates the changes to coding, to enable check boxes to allow more than one response to be submitted. This provides more detailed information about the applicant, as it allows for as much information as possible to be selected.

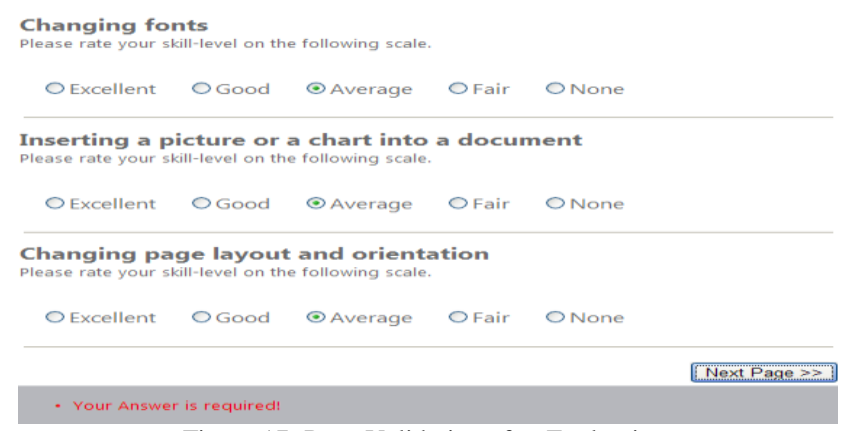

Figure 17: Page Validation after Evaluation
An additional validation error message was added to alert the applicant of required answers. As a result, the page now displays one message at the top, and one message at the very bottom of the page. These two error messages advise the applicant that a mandatory question has not been answered, without having to scroll up through a long page to check messages. Instead, the applicant will see any error messages at the bottom of the page near the 'Next Page' button upon attempting to submit.

\section{CONCLUSION}

The use of modern technology in the health industry demands that employees are given adequate training to ensure a productive work environment. Austin Health recognizes that effective training measures should be in place to ensure that nurses have the requisite skills to work with the relevant electronic systems.

Austin Health observed that the current method used for training nurses was time consuming, uneconomical and generally inefficient. In particular, the disparity between nursing roles meant that a one size fits all training approach was not appropriate, as it failed to take into account the different training needs of each nurse.

In response to these concerns, Austin Health considered replacing its existing training method with a new system that would identify the current skill level and specific skill-set required for existing and new nurses. Taking into account the various alternatives to the current method, Austin Health considered the development of a web-based survey as an appropriate training solution. Through ongoing consultation with the first author and further research gathered, SKAT was developed to meet Austin Health's objectives. The system uses a web-based adaptive questionnaire designed and developed in accordance with the principles of the Training Needs Analysis (TNA). The ultimate result is a training system that provides efficient targeted training, through personalized training schedules within time and costs constraints.

The design of SKAT developed through a process which began with the design of an efficient database system, defining a data type for each attribute and entering data into the database. This process follows through to the coding of SKAT, which is inextricably linked to the design of the system, as coding is applied according to the design.

Upon completion the coding stage, the third and the forth authors provided an evaluation of SKAT, and changes were applied according to their feedback. A pilot evaluation was undertaken by staff in two different nursing roles, and their suggestions were discussed and applied to the system. This process concluded with a full evaluation of SKAT, and involved applying final changes to the system based on feedback provided by evaluators, before delivering the final version of SKAT to the client.

\section{FUTURE WORK}

Although SKAT was designed, implemented and evaluated after its completion, there still many functions which could be added to the system. 
- Adding a progress bar to each page of the questionnaire. This function helps the applicant to track progress throughout the completion of the questionnaire.

- $\quad$ Applying SKAT to different professions. This system can be easily applied to other professions by implementing appropriate requirements to form a relevant questionnaire.

- $\quad$ Automatic sending of applicant's results to managers. This function will enable applicant's reports to be automatically attached to an email, and sent to the applicant's manager.

- $\quad$ SKAT can automatically connect to other systems. The system can share information about results generated in SKAT by connecting with other systems, such as Chris 21, the Human Resources system at Austin Health, which can book training sessions for applicants based on results generated from their questionnaire.

- $\quad$ SKAT will automatically send each applicant an email with a link to begin the survey. Individuals can then access and complete the survey from any location such as home or work, and all responses will be saved automatically on the server.

Although some of these features are not critical, they would all clearly provide a great amount of benefit to SKAT if implemented.

\section{ACKNOWLEDGMENT}

There are many individuals who contributed to the successful completion of this thesis through their sport, advice or participation. We must single out Sarah Tawil for her support and assistance in checking and advising writing the thesis. We are also grateful to Russell Paulet for his assistance in programming and technical support.

\section{REFERENCES}

[1] http://www.austin.org.au/about_us/

[2] F. Nightingale, Notes on Nursing: What It Is and What It Isn't. Dover, New York, 1859.

[3] J. Murphy, "The Intersection of Nursing, Computer, and Information Sciences. Nursing Economics," Nursing Informatics, 2010, vol. 28, p. 3.

[4] J. Kelly, "Computer in hospitals nursing practice defined and validated," Department of Nursing, New York University Medical Centre, 1983, vol. 83, pp. 195-210.

[5] M. Ball, K. Hannah, Using computers in nursing. Reston, VA: Reston Publishers, 1984.

[6] M. Scholes, the Impact of Computers in Nursing: an International Review.North-Holland, Amsterdam, 1983.

[7] J. J. Beckers, H. J. Schmidt, "Computer experience and computer anxiety," Computers in Human Behavior, 2003, vol. 19, pp. 785-797.

[8] J. J. Beckers, H. J. Schmidt, "The structure of computer anxiety: a sixfactor model," Computers in Human Behaviour, 2001, vol. 17, pp. 3549.

[9] Bureau of Labor Statistics, Occupation outlook handbook 2004, 5 edition Registered nurses, 2003.

[10] E. Goorman, M. Berg, "Modelling nursing activities: electronic patient records and their discontents," Nursing Inquiry, 2000, vol. 7, pp. 3-9.

[11] R. E. Dick, E. Steen, The Computer based Patient Record: An Essential Technology for Healthcare. National Academy Press, Washington D.C., 1991.

[12] S. Bakken, "An informatics infrastructure is essential for evidencedbased practice," Journal of the American Medical Informatics
Association, 2001, vol. 8, pp. 199-201.

[13] R. Gururajan, S. Murugesan, J. Soar, "Introducing Mobile Technologies in Support of Healthcare," Journal of Information Technology Management. 2005, vol. 18, pp. 12-18.

[14] W. W. Jiang, W. Chen, Y. C. Chen, "Important Computer Competencies for the Nursing Profession," Nursing Research, 2004, vol. 12.

[15] American Nurses Association, "Scope and standards of nursing informatics practice," Washington, DC: American Nurses Publishing 2001.

[16] H. M. Hsu, Y. H. Hou, I. C. Chang, D. C. Yen, "Factors Influencing Computer Literacy of Taiwan and South Korea Nurses," J Med Syst, 2009, vol. 33, pp. 133-139.

[17] N. Staggers, C. A. Gassert, C. Curran, "Informatics Competencies for Nurses at Four Levels of Practice," Nursing Education, 2001, vol. 40.

[18] M. C. Wallace, A. Shorten, P. A. Crookes, C. McGurk, C. Chris Brewer, "Integrating information literacies into an undergraduate nursing programme," Nurse Education Today, 1999, vol. 19, pp. 136-141.

[19] "European Computer Driving License", 2011, from http://www.ecdl.org/index.jsp?p=93\&n=94.

[20] Nursing Informatics Australia, (NIA), 2001. Position Statement. Integration of Nursing Informatics into Nursing Education.

[21] L. Friend, "Nursing Unit Manager Job Description", 2011, from http://www.ehow.com/about_6331258_nursing-unit-manager-job description.html\#ixzz1 VCL67nOP

[22] J. Robertson, "Assistant Director of Nursing Services Job Description", 2011, from http://www.ehow.com/about_6330371_assistant-nursing servicesjobdescription.html\#ixzz1VCOlJUuv

[23] W. Thibodeaux, "Assistant Nurse Manager Job Description", 2011, from http://www.ehow.com/about_6551492_assistant-nurse-manager-jobdescription.html\#ixzz1 VLDY gZ8m

[24] L. Kelchner, "Job Description of a Clinical Nurse Specialist", 2011, from http://www.ehow.com/about_6739002_job-description-clinicalnurse-specialist.html\#ixzz1 Vou0Ok9S

[25] M. Codjia, "Clinical Nurse Consultant Job Description", 2011, from http://www.ehow.com/facts_6803456_clinical-nurse-consultant-jobdescription.html\#ixzzlVCRG5F9k

[26] J. Gogler, Assistant Director of Nursing, Nursing Informatics, Austin Health, 2011.

[27] "Job Description for an RN Nurse", 2011, from http://www.ehow.com/facts_4840477_job-description-rnnurse.html\#ixzz1 VpMWwwnI

[28] J. Price, "Job Description of an Enrolled \& Endorsed Nurse", 2011, from http://www.ehow.com/facts_7207795_job-description-enrolledendorsed-nurse.html\#ixzz1WHwChC9c

[29] Kronos, Australia Pty Limited is a Government Endorsed Supplier, 2011, form http://www.kronos.com.au/about-kronos/about-kronosaustralia.aspx

[30] TrakHealth Pty Ltd, 2004, from http://www.consensus.com.au/SoftwareAwards/CSAarchive/CSA2006/ TrakHealth.htm

[31] InfoMedix, wholly-owned subsidiary of Object Consulting Pty Ltd Australian Software Development Company, 2011, from, http://www.infomedix.com.au/

[32] Accenture, Medical Imaging, 2011, from http://www.accenture.com/auen/landing-Pages/health-public-service/Pages/healthps-au-find-theoptimal-medical-imaging-solution-withhealthanalytics.aspx? $=$ con_auglohpsgs_1210\&n=g_medical_imaging_/ a_0_k/pacs\&KW_ID=33bde296-636a-51e9-42c7-000034b89524

[33] MEDIVISION, Health-Care informatics, "IMPAX, Agfa-Web 1000", 2006, from http://www.medivision.co.il/agfa-WEB1000.htm

[34] RiskMan International (RMI), 2011, from http://www.riskman.net.au/

[35] Microsoft Partner, Health-e Workforce Solutions, 2011, from http://www.healthewfs.com.au/

[36] Frontier Software, Comprehensive Human Resource Integrated Solution, Chris21, 2011, from http://www.frontiersoftware.com/products/chris21integrated-human-resource-management-payroll 